\title{
DEPRESSION AND SELF-ESTEEM IN EARLY ADOLESCENCE
}

\author{
Ingrid Tripković ${ }^{1}$, Romilda Roje ${ }^{2}$, Silvana Krnić², Mirjana Nazor ${ }^{3}$, Željka Karin ${ }^{1}$, Vesna Čapkun ${ }^{2}$ \\ ${ }^{1}$ Public Health Institute of Split and Dalmatia County, Split, Croatia \\ ${ }^{2}$ Clinical Hospital in Split, Split, Croatia \\ ${ }^{3}$ Faculty of Science, University of Split, Split, Croatia
}

\section{SUMMARY}

Aim: Depression prevalence has increased in the last few decades, affecting younger age groups. The aim of this research was to determine the range of depression and low self-esteem in elementary school children in the city of Split. Testing was carried out at school and the sample comprised 1,549 children (714 boys and 832 girls, aged 13$)$.

Methods: Two psychological instruments were used: the Coopersmith Self-Esteem Inventory (SEI) and the Children and Adolescent Depression Scale (SDD).

Results: The average value of scores obtained by SEl test was 17.8 for all tested children. No statistically significant difference was found between boys and girls. It was found that $11.9 \%$ of children showed signs of clinically significant depression, and $16.2 \%$ showed signs of depression. Statistically significant association between low self-esteem and clinically significant depression was found. No statistically significant difference among boys and girls according to dimension of cognitive depression was found, whereas statistically significant level of emotional depression was higher in girls than boys. It was found that both dimensions of depression decreased proportionally with the increase of SEl test score values: cognitive and emotional dimension of depression.

Conclusion: The results of this study show that it is necessary to provide early detection of emotional difficulties in order to prevent serious mental disorders.

Key words: depression, adolescents, emotional difficulties, self-esteem, prevention

Address for correspondence: I. Tripković, Public Health Institute of Split and Dalmatia County, Vukovarska 46, 21000 Split, Croatia. E-mail: ingrid_tripkovic@net.hr

\section{INTRODUCTION}

Depression prevalence has increased in the last few decades, affecting younger age groups. According to WHO, depression is the 4th leading disease and by 2020 it is expected to reach the 2nd place.

It was believed for a long time that children and adolescents cannot suffer from depression as a clinical disorder, since depression has been just one of the symptoms of developmental phases. Today, we are aware of the fact that depressive disorder represents serious disorder with potential occurrence in childhood. Depression in this vulnerable population is associated with the increased risk of developing of other psychiatric disorders, low academic, social and working abilities as well as drug abuse and addiction, and suicide (1-3).

Depressed children occasionally show excessive activity and aggression. Adolescent depression sometimes includes negativism, antisocial behaviour and feelings of being misunderstood. Depression rarely includes all the above mentioned symptoms. It is estimated that $10-15 \%$ of children in general population show severe symptoms of depression (4).

Systematic researches of depression in children and adolescents have started in the 1980s, and they indicate that the symptoms of depression in children and adolescents were similar to those in adults (5).
Studies have shown that the prevalence of depression in childhood increases proportionally with the age. The lowest prevalence rate has been reported in pre-school children (approximately $1 \%$ ) and it increases in adolescents (approximately $3 \%$ in boys and $10 \%$ in girls) $(4,6)$. Symptoms of depression change as children grow up. Thus, in the period of middle childhood (from 6-12 years) low self-esteem, pessimism, physical complaints, and unauthorised absence from school are prevalent among signs and symptoms. Adolescent group show dominant signs and symptoms of guilt, hopelessness and helplessness. Based on theoretical, clinical and empirical knowledge of depression symptomatology in childhood and adolescence, it is possible to recognize three groups of depression symptoms. Cognitive symptoms include signs of low self-esteem, guilt, communication problems, difficulty in making decisions, preoccupation with death and suicide (7). Emotional symptoms include bad mood, sadness, hopelessness, discouragement, apathy, irritability, lack of motivation or pleasure in usual activities as well as fatigue and loss of energy. Physical symptoms include weight loss or overweight, insomnia or excessive sleeping, and psychomotor agitation $(8,9)$.

The aim of this research was to determine the range of emotional difficulties (primarily depression and low self-esteem) in elementary school children in the city of Split. 


\section{MATERIALS AND METHODS}

Parental informed consent was sent as a request to the parents of all 2,222 elementary school children attending 7th grade (aged 13) in the City of Split. The informed consent was obtained for 1,728 children, but 1,549 children ( 714 boys and 832 girls) were present when the study was performed. Testing was carried out at school under supervision of school psychologist. The children filled in questionnaires by themselves. Each child was tested using two psychological instruments: the Coopersmith Self-Esteem Inventory (short version, Bezinović and Lacković-Grgin, 1990) and the Children and Adolescent Depression Scale (Vulić-Prtorić A., 2003).

In this study an adapted short version of the Coopersmith Self-Esteem Inventory (SEI) test (Bezinović, Lacković-Grgin, 1990, according to Lacković-Grgin and associates, 2002) was used. The questionnaire was designed to assess self-esteem. The questionnaire consisted of 25 items, using forced-choice (accurate/ inaccurate) format. The result reflected global measure of selfesteem. Confidence scale varied from $0.77-0.79$ (Cronbach alfa).

The Children and Adolescent Depression Scale (SDD) is depression scale for children and adolescents aged 10-18, and it was based on the symptom list of DSM IV classification. The scale consisted of 26 statements describing the most common depression symptoms in children and adolescents (mood disorder, loss of interest, appetite and sleeping disorder, psychomotor disabilities, hopelessness, resignation, loss of energy, etc.). It was possible to distinguish between cognitive-motivational and emotional-physical components of depression. The examinees, using corresponding five-point grading scale, assessed the accuracy of statements according to their opinion $(1=$ not accurate at all, $2=$ mostly inaccurate, $3=$ not sure, $4=$ mostly accurate, $5=$ yes, completely accurate). The confidence for the complete twenty six-point grading scale was valid (Cronbach alfa 0.895). Evaluation of their answers was performed by summing the whole numbers beside each statement. The obtained scores were transformed into decile rank by using the appropriate manual table where norms were established (up to 3 deciles $=$ low average score; from 3-6 deciles = average score; above 6 deciles = high average score and 9-10 deciles = clinically significant score). Median, lower and upper quartiles were also calculated in order to compare the results of SDD and SEI tests.

\section{RESULTS}

The results of 1,549 children ( 714 boys and 832 girls) were analyzed. The average value of scores obtained from SEI test was 17.8 for all tested children, 18 for boys and 17.6 for girls. No statistically significant difference between boys and girls was found $(\mathrm{p}=0.098)($ Table 1$)$.

Table 1. The mean values $\pm S D$ and medians (min-max) at SEI test according to the gender

\begin{tabular}{|l|c|c|c|c|}
\hline SEl test & Total & Boys & Girls & \multirow{2}{*}{$\mathbf{p}^{*}$} \\
\hline \multirow{yyyyn}{*}{ SD } & $17.8 \pm 4.97$ & $18 \pm 4.6$ & $17.6 \pm 5.2$ & \multirow{2}{*}{0.098} \\
\cline { 1 - 4 } Median & 19 & 19 & 19 & \\
\cline { 1 - 3 } Min-max & $1-25$ & $1-25$ & $1-25$ & \\
\hline
\end{tabular}

Boys and girls were divided into four groups regarding SEI test points. The first group $(<15$ : extremely low self-esteem) consisted of 372 children, 155 boys and 217 girls. The second group (15-19: low self-esteem) consisted of 384 children, 186 boys and 198 girls. The third group (19-22: average self-esteem) consisted of 377 children, with 191 boys and 186 girls. The fourth group ( $>22$ : high self-esteem) consisted of 412 children, 182 boys and 230 girls. Statistical data analysis showed $96 \%$ probability of difference between boys and girls (Figure 1).

The average value of SEI test scores for boys was within average category, whereas for girls, values were within extreme categories (values were grouped below or above average values).

According to the scores obtained from children on the Children and Adolescent Depression Scale (SDD), children were grouped into four groups with clinically significant scores, high average scores, average scores and low average scores.

It was found that $153(11.9 \%)$ children showed signs of clinically significant depression and $250(16.2 \%)$ showed signs of depression (Figure 2).

According to SDD scale the frequency of depression based on the score points of SEI test was also investigated within each group. Statistically significant association between low self-

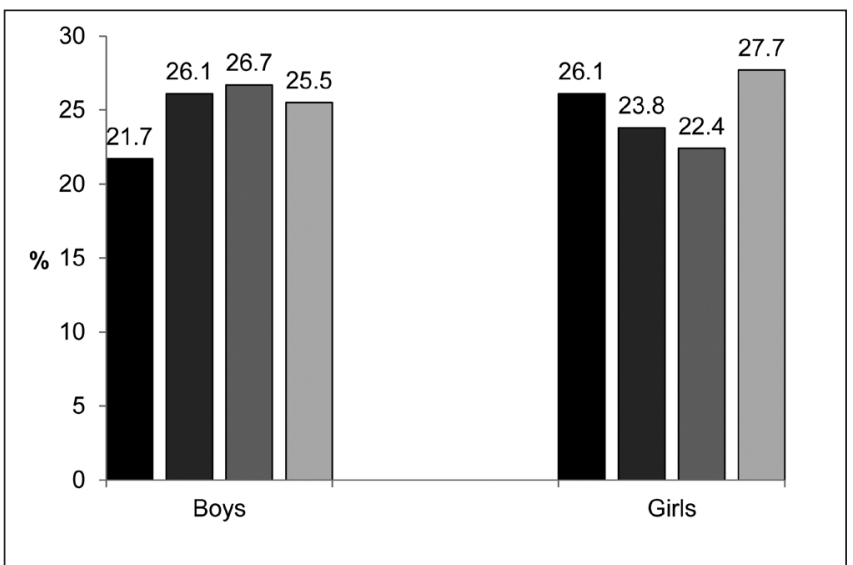

Fig. 1. The frequency distribution of categorized SEl test scores $\left(X^{2}=7.55 ; p=0.056\right)$ according to the gender (<15 black; 15-18 dark grey; 19-21 grey; $\geq 21$ pale grey column).

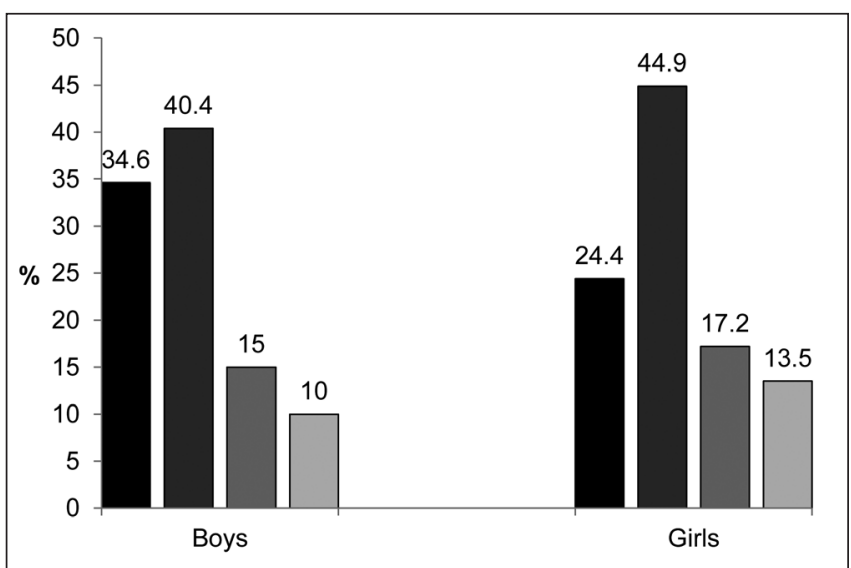

Fig. 2. The frequency distribution of SDD scores according to the gender (I and II decile - black; III, IV, V and VI decile - dark grey; VII and VIII decile - grey; IX and X decile - pale grey column). 
esteem and clinically significant depression was found $\left(\chi^{2}=852\right.$; $\mathrm{p}<0.001)$. Furthermore, 7 times more children with the scores categorized in I and II deciles fell into the group with 15-18 points, than into the group with less than 15 points at the SEI test. There were 23 times more children with the scores categorized in I and II deciles having score points from 19-22, in relation to the group with the scores less than 15. There were 39 times more children with the results categorized in I and II deciles in the group with more than 22 points, than in the group with less than 15 points (Figure 3 ).

The frequency of two dimensions of depression: cognitive and emotional-physical in boys and girls was also investigated. No statistically significant difference among boys and girls according to dimension of cognitive depression was found $(\mathrm{z}=0.077$; $\mathrm{p}=0.939$ ), whereas statistically significant level of emotional depression was higher in girls than boys $(z=9.39$; $p<0.001)$ (Table 2).

The scores for cognitive and emotional dimension of depression according to SDD test in the groups based on the point score

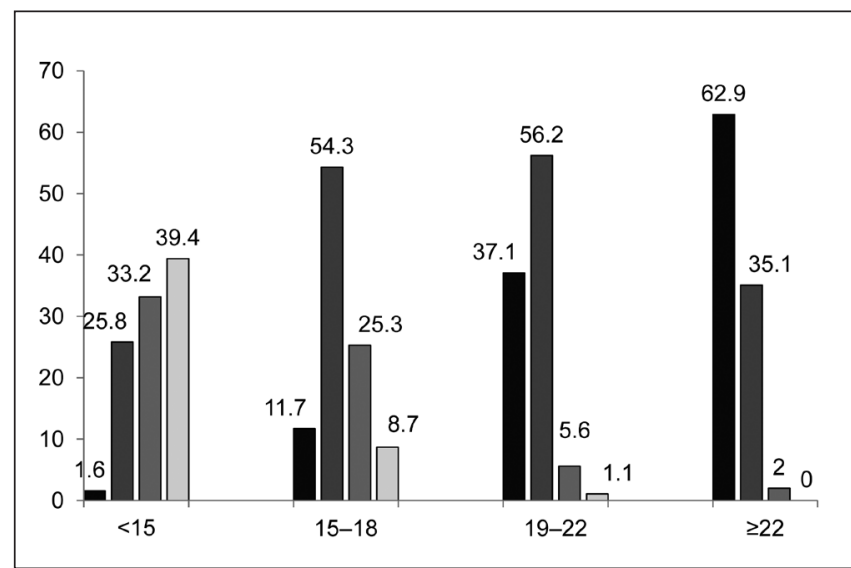

Fig. 3. SDD scores in the groups of categorized SEl test scores (I and II decile - black; III, IV, V and VI decile - dark grey; VII and VIII decile - grey; IX and X decile - pale grey column).

Table 2. The mean values, medians (min-max) of cognitive and emotional depression at SDD test according to the gender

\begin{tabular}{|l|c|c|c|}
\hline Depression & Boys & Girls & $\mathbf{p}^{*}$ \\
\hline \multirow{2}{*}{ Cognitive } & $27.6 \pm 10.2$ & $27.9 \pm 10.8$ & \multirow{2}{*}{0.939} \\
\cline { 2 - 3 } & $25(16-79)$ & $25(16-76)$ & \multirow{2}{*}{$<0.001$} \\
\hline \multirow{2}{*}{ Emotional } & $18.2 \pm 5.9$ & $21.3 \pm 6.8$ & \multirow{2}{*}{} \\
\cline { 2 - 3 } & $17(10-44)$ & $21(10-50)$ & \\
\hline
\end{tabular}

*Mann-Whitney test of SEI test were analyzed. It was found that both dimensions of depression decreased proportionally with the increase of SEI test score values: cognitive $\left(\chi^{2}=754 ; \mathrm{p}<0.001\right)$ and emotional dimension of depression $\left(\chi^{2}=435 ; \mathrm{p}<0.001\right)$ (Table 3$)$.

Statistically significant difference in the distribution of SDD test scores according to the groups of SEI test was found $\left(\chi^{2}=852\right.$; $\mathrm{p}<0.001)$. In the SEI group of $>22$ there were no children with SDD test score of $\geq 67$, and there were only $2 \%$ with SDD test score from 54-66. In the SEI group of $<15$ there were only $1.6 \%$ children with SDD test score from 26-37. The number of children with low self-esteem increased proportionally with the increased SDD test scores. In the SEI group of $>22$ the frequency of children with SDD test scores from 26-37 was 39 times higher in relation to $\mathrm{SEI}<15$, and 5.4 times higher than in the SEI group from 15-19, and 1.7 times higher than in the SEI group from 19-22. In the $\mathrm{SEI}<15$ group, there were 4.6 times more children with SDD score $\geq 67$ than in the SEI group from 15-19 and 35.8 times higher in relation to the SEI group from 19-22 (Table 4).

\section{DISCUSSION}

Coopersmith defines self-esteem as self-evaluation that maintains our attitude of accepting or not accepting ourselves. Selfesteem is a life development process, not only as a reflection of our own judgement, but resulting from reactions of other important persons as well. Children who have been accepted, respected and approved in the process of growing-up, will accept their both positive and negative characteristics, developing the appropriate level of self-esteem. In this research, according to the Coopersmith test scores, it was found that boys were within the average category, while trend of grouping within extreme categories (below or above average values) was noted in girls. According to Burns (10), self-esteem is largely affected by parental evaluation of younger children, while in elder children parental influence is less relevant. Furthermore, the level of self-esteem in girls is more affected by parental evaluation than in boys. According to our SDD test scores it was found that $11.9 \%$ of tested children showed signs of clinically significant depression and $16.2 \%$ of children showed signs of depression. It was also found that children with high level of self-esteem had significantly less symptoms of depression, meaning that children with substantial depressive symptoms exhibited low self-esteem. In the group of children with high self-esteem there were no children with substantial depressive symptoms. It was also found that depressive symptoms were more prevalent in girls than in boys and symptoms of emotional-physical dimension of depression were more prominent in girls. Since the score points of self-esteem and depression test were inversely proportional, it

Table 3. The mean values, medians (min-max) of cognitive and emotional depression at SDD test according to SEI test groups

\begin{tabular}{|l|c|c|c|c|c|}
\hline \multirow{2}{*}{ Depression } & \multicolumn{5}{|c|}{ Groups according to SEl test scores } \\
\hline \multirow{2}{*}{ Cognitive } & $<15$ & $15-19$ & $\geq 19-22$ & $>22$ & $\mathbf{p}^{*}$ \\
\hline \multirow{2}{*}{ Emotional } & $39.4 \pm 11.8$ & $28.8 \pm 7.6$ & $23.2 \pm 5.4$ & $20.5 \pm 3.9$ & $<0.001$ \\
\cline { 2 - 6 } & $37(16-79)$ & $28(16-56)$ & $22(16-49)$ & $20(16-44)$ & \\
\cline { 2 - 6 } & $25 \pm 7$ & $21 \pm 5.8$ & $17.9 \pm 4.9$ & $15.8 \pm 4.4$ & $<0.001$ \\
\hline
\end{tabular}


Table 4. SDD test score distribution according to SEI test groups in children

\begin{tabular}{|c|c|c|c|c|c|c|}
\hline \multirow[b]{2}{*}{ SDD test scores } & \multicolumn{6}{|c|}{ Groups according to SEl test scores } \\
\hline & $<15$ & $15-19$ & $\geq 19-22$ & $>22$ & Total & $p^{*}$ \\
\hline $26-37$ & $6(1.6)$ & $45(11.7)$ & $140(37.1)$ & $258(62.9)$ & $449(29.1)$ & \multirow{5}{*}{$<0.001$} \\
\hline $38-53$ & $96(26)$ & $208(54.2)$ & $212(56.2)$ & $144(35.1)$ & $660(42.8)$ & \\
\hline $54-66$ & $123(33.2)$ & $97(25.3)$ & $21(5.6)$ & $8(2.0)$ & $249(16.2)$ & \\
\hline$\geq 67$ & $146(39.4)$ & $33(8.6)$ & $4(1.1)$ & 0 & $183(11.9)$ & \\
\hline Total & $371(100)$ & $383(100)$ & $377(100)$ & $410(100)$ & $1541(100)$ & \\
\hline
\end{tabular}

${ }^{*} x^{2}$ test

might indicate that children with low self-esteem could be at risk for developing depressive symptomatology. That did not necessarily mean that depression level would reach a clinically significant level. This correlation strongly indicates the necessity of preventive measures. Preventive treatment is efficient in decreasing of depressive symptoms in children with more risk factors for the development of depression.

Self-image affects our way of functioning. Permanent low selfesteem has an impact on mood and a child becomes more prone to depression and other mental health disorders. Therefore, the most efficient treatment is the multimodal one, directed not only at depressive symptoms, but the overall problems in functioning as well. In the treatment of children and adolescents with depression medication is rarely indicated as the only strategic therapy, isolated from other psychosocial interventions (11). Some studies show that in pre-adolescent period, boys show more depressive symptoms than girls (4). However, in girls reported symptoms of depression rapidly developed in early adolescence, while boys remain stable. There are also theoretical explanations for the increased depressive symptoms in adolescence reported in girls $(12,13)$. Some theories show that psychological changes in adolescence increase the risk of depression in girls. Furthermore, girls in adolescence start worrying about their appearance. They can also be sensitive to signals (verbal or nonverbal) sent by other people in relation to whether their behaviour is acceptable or not (14). Petersen et al. (15) conducted longitudinal study where 335 subjects were followed up from early adolescence to adulthood. The results showed that the level of depression increased during adolescence in girls, whereas it was stable in boys. Girls were more depressed in early adolescence and these differences were statistically significant. According to gender, differences in the level of depression were more relevant during adolescence, which was indicated by significant interaction between age and gender. The differences in depression level of boys and girls were more obvious with ageing.

The early treatment is therefore directed at self-esteem enhancement and stimulation of positive thinking in order to decrease the risk of chronic psychosocial damage. It means that the role of educational institutions is crucial since their early detection of low self-esteem can screen population with potential risk of depression disorder development. Prevention of mental disorders in childhood and adolescence significantly affects mental health during middle and older age.

\section{CONCLUSION}

The results of this study indicate that it is necessary to organize early detection as well as early intervention in order to avoid serious mental disorders in later adolescence and adult age. Therefore, this problem demands multidisciplinary approach including educational system, healthcare system and social welfare system. The Ministry of Science, Education and Sports can help in dealing with this issue by organizing of educational courses for teaching personnel.

\section{Ethical Approval}

This study was conducted with the approval of the Public Health Institute of Split and Dalmatia County Ethics Committee.

\section{REFERENCES}

1. Morgan JK, Shaw DS, Forbes EE. Physiological and behavioral engagement in social contexts as predictors of adolescent depressive symptoms. J Youth Adolesc. 2013 Aug;42(8):1117-27.

2. Brauner CB, Stephens CB. Estimating the prevalence of early childhood serious emotional/behavioral disorders: challenges and recommendations. Public Health Rep. 2006 May-Jun;121(3):303-10.

3. Breton JJ, Labelle R, Huynh C, Berthiaume C, St-Georges M, Guilé JM Clinical characteristics of depressed youths in child psychiatry. J Can Acad Child Adolesc Psychiatry. 2012 Feb;21(1):16-29.

4. Merikangas KR, Nakamura EF, Kessler RC. Epidemiology of mental disorders in children and adolescents. Dialogues Clin Neurosci. 2009;11(1):7-20.

5. Kazdin AE, Marciano PL. Childhood and adolescent depression. In: Barkley RA, Masch EJ, editors. Treatment of childhood disorders. 2nd ed. New York: Guilford Press, 1998. p. 211-48.

6. Compas BE. Depression in children and adolescents. In: Mash EJ, Terdal LG, editors. Assessment of childhood disorders. 3rd ed. New York: Guilford Press, 1997. p. 197-229.

7. Castaneda AE, Tuulio-Henriksson A, Marttunen M, Suvisaari J, Lönnqvist J. A review on cognitive impairments in depressive and anxiety disorders with a focus on young adults. J Affect Disord. 2008 Feb;106(1-2):1-27.

8. Lu Y, Mak KK, van Bever HP, Ng TP, Mak A, Ho RC. Prevalence of anxiety and depressive symptoms in adolescents with asthma: a meta-analysis and meta-regression. Pediatr Allergy Immunol. 2012 Dec;23(8):707-15.

9. Baji I, Gádoros J, Kiss E, Mayer L, Kovács E, Benák I, et al. Symptoms of depression in children and adolescents in relation to psychiatric comorbidities. Psychiatr Hung. 2012;27(2):115-26. (In Hungarian.)

10. Burns RB. Self-concept development and education. London: Holt, Rinehart and Winston, 1982.

11. Clark MS, Jansen KL, Cloy JA. Treatment of childhood and adolescent depression. Am Fam Physician. 2012 Sep 1;86(5):442-8.

12. Romeo RD. Adolescence: a central event in shaping stress reactivity. Dev Psychobiol. 2010 Apr;52(3):244-53.

13. Dahl RE, Gunnar MR. Heightened stress responsiveness and emotiona reactivity during pubertal maturation: implications for psychopathology. Dev Psychopathol. 2009 ;21(1):1-6.

14. Hetherington JA, Stoppard JM. The theme of disconnection in adolescent girls' understanding of depression. J Adolesc. 2002 Dec;25(6):619-29.

15. Petersen AC, Sarigiani PA, Kennedy RE. Adolescent depression: Why more girls? J Youth Adolesc. 1991 Apr;20(2):247-71. 